\title{
Left ventricular function at 24 hours, 14 days and 6 months after acute myocardial infarction
}

\author{
A. Righetti, V. Podio, O. Ratib, C. Jost, V. Stucki and A.-F. Müller \\ Cardiology Center and Internal Medicine Department, University Hospital, Geneva, Switzerland
}

KEY WORDS: Myocardial infarction, radionuclide angiocardiography, serial left ventricular function.

To determine the natural history of left ventricular function at rest and during exercise and to assess the impact of this variable on subsequent mortality, 165 patients were studied with radionuclide angiography within 24 hours of acute myocardial infarction. The ejection fraction of the 19 patients who died during the 6 month follow-up was lower than that of the 146 survivals: $41 \pm 16 \%$ vs $50 \pm 13 \%(\mathrm{P}<0.001)$. Before hospital discharge (14 4 days), 83 patients had a rest and submaximal exercise radionuclide study. The ejection fraction of the 42 patients with anterior infarction was $44 \pm 12 \%$ and remained unchanged during exercise, while the 41 patients with posterior infarction had a resting value of $54 \pm 9 \%$ which increased to $57 \pm 10 \%$ $(\mathrm{P}<0.001)$ during exercise. The ejection fraction during exercise increased slightly but significantly in $37 / 61$ patients with single vessel disease, while it did not change in the 24/61 patients with multivessel disease. At a mean of $4 \pm 1$ months following infarction, 58 patients underwent a symptom-limited exercise radionuclide study. Mean value of resting ejection fraction for the group or anterior-posterior infarction subgroups did not change from initial or predischarge values. The 27 patients with anterior infarction showed no change in ejection fraction during exercise, while the 31 patients with posterior infarction increased their ejection fraction from $53 \pm 11 \%$ to $57 \pm 12 \%(\mathrm{P}<0.001)$. Thus, ejection fraction measured by radionuclide angiography 24 hours following acute myocardial infarction provides useful prognostic information. Moreover, data collected 14 days and 4 months after infarction indicate that no significant change in ejection fraction occurred at rest or during exercise compared with values at rest for the group as a whole. However, ejection fraction values of patients with posterior infarction or of patients with single vessel disease increased with exercise. indicating that after myocardial infarction the capacity for improvement in myocardial function does exist in those patients who manifest the least extensive ischaemic or necrotic damage.

Left ventricular function is an important factor in the identification of high-risk and low-risk patients following acute myocardial infarction ${ }^{[1 \cdot 4]}$. Radionuclide techniques provide noninvasive means of evaluating ventricular performance in patients following acute myocardial infarction ${ }^{[515]}$. Some disparity has been observed between left ventricular function values in the acute phase and the recovery phase following infarction ${ }^{(16)}$. Moreover, the left ventricular function determined with the patient at rest, often shows little relationship to the extent of ventricular dysfunction determined during exercise $^{[16 / 7]}$. This report describes a prospective study of left ventricular performance in patients with acute myocardial infarction using gated equilibrium radionuclide angiography. The goals were two-fold: (1) to assess left ventricular performance during the early phase of an acute myocardial infarction and to measure the impact of this variable

Address for correspandence: Dr Alberto Righetti, Cardiology Center, University Hospital of Geneva, 1211 Geneve 4, Switzerland. on subsequent mortality and (2) to determine the natural history of left ventricular function at rest and during exercise over a 6 month follow-up period.

\section{Methods}

STUDY POPULATION

Studies were performed on 165 patients admitted to the intensive Care Unit of the University Hospital of Geneva in late 1983 and during 1984 with the diagnosis of acute myocardial infarction. There were 34 women and 131 men with mean age of 58 years (range 37 to 79). The diagnosis of acute myocardial infarction was based on the following criteria: (1) a history of typical, prolonged chest pain, (2) electrocardiographic changes indicative of myocardial injury including ST-segment depression $\geq 1.0 \mathrm{mV}$, a newly developed QS complex or $\mathrm{Q}$ waves of $\geq 0.04$ seconds duration, and (3) abnormal elevation of creatine kinase and of the creatine kinase cardiac isoenzymes. The location of the 
infarction was determined using standard electrocardiographic criteria and patients were classified as having anterior (antero-septo-apical) or posterior (infero-posterior) myocardial infarction.

\section{STUDY PROTOCOL}

All 165 patients underwent a first radionuclide anglography as early as technically possible after the onset of symptoms $(29 \pm 18$ [mean \pm 1 standard deviation] hours). Eighty-three patients were submitted to rest and submaximal exercise radionuclide angiography before hospital discharge, if they presented with an uncomplicated post infarction course; recurrent angina, decompensated congestive heart failure and severe arrhythmias being exclusion criteria.

Selective coronary angiography was performed in 127 patients, $32 \pm 48$ days after the acute myocardial infarction. Cineangiograms were analyzed by two cardiologists who were not investıgators in this study. A reduction $\geq 70 \%$ of the luminal diameter of at least one major coronary artery was required to diagnose significant coronary artery disease. Fifty-eight patients were submitted to rest and symptom-limited radionuclide angiography, $4 \pm 1$ months following the acute event. Of these 58 patients, 35 had a previous rest-exercise radionuclide study at the time of discharge from the hospital.

Radionuclide angiography was obtained with the gated equilibrium method utilizing the in vivo-in vitro red cell labelling technique. With the patient supine, images were obtained in the anterior and left anterior oblique projections, the latter generally done at $35-50^{\circ}$ with a caudal tilt of $10-15^{\circ}$ in order to best separate the left from the right ventricle in the field of view. The mobile gamma camera was coupled with a commercial nuclear medicine computer and data were collected in $64 \times 64$ matrix gated in 16 equal frames by a digitized electrocardiogram. Counts were acquired at rest until a pixel reached a value of 255 and during exercise until 5 minutes aquisition or when at least 4 million counts were reached. The images were timecorrected, space- and time-smoothed, then left ventricular ejection fraction was calculated by at least two observers with a standard technique using the background-corrected activity from the regions of interest manually constructed over the left ventricle at end-diastole and end-systole.

Graded supine bicycle ergometry performed in conjunction with radionuclide angiography commenced at a work load of 25 or 50 watt and increased by 25 watt every 3 minutes. The electrocardiogram was continuously monitored and blood pressure was recorded at 3 minutes intervals during exercise and recovery.

DATA ANALYSIS

All data are expressed as the mean \pm 1 standard deviation. Multiple inter- or intragroup comparisons were analyzed by paired or unpaired Student $t$-tests.

\section{Results}

Of the 165 patients, 19 died of cardiac causes, 14 of them during the initial hospitalization period and 5 within 3 months of discharge from the hospital. The mean left ventricular ejection fraction of the 19 patients who died during the total follow-up period was significantly lower $(41 \pm 16 \%)$ than the mean initial ejection fraction for the 146 survivors $(50 \pm 13 \%, P<0.01)$.

\section{REST-EXERCISE RADIONUCLIDE STUDIES BEFORE} HOSPITAL DISCHARGE

Two weeks following uncomplicated myocardial infarction, mean left ventricular ejection fraction at rest in 83 patients was $49 \pm 12 \%$ practically unchanged from the initial ejection fraction $(50 \pm 13 \%)$. Of these 83 patients, $42 \mathrm{had}$ an anterior and 41 a posterior myocardial infarction. The initial mean ejection fraction of the 42 patients with anterior myocardial infarction was significantly lower than that of the patients with posterior infarction $(44 \pm 13 \%$ vs $56 \pm 11 \%, P<0.001)$. Before hospital discharge mean ejection fraction of the patients with anterior infarction did not change from day 1 , while it decreased slightly to $54 \pm 9 \%$ $(P<0.05)$ in patients with posterior myocardial infarction (Table 1). During a submaximal exercise stress test the mean work load was $55 \pm 9 \%$ watts, the heart rate increased from $71 \pm 13$ to $112 \pm 16$ beats per minute and systolic blood pressure increased from $123 \pm 16$ to $166 \pm 22 \mathrm{mmHg}$.

During exercise mean ejection fraction of the 42 patients with anterior myocardial infarction did not change, while it increased significantly to $57 \pm 10 \%$ $(P<0.001)$ in the 41 patients with posterior infarction (Table 2). Of the 83 patients, 61 underwent coronary angiography; 37 of these had a significant lesion of one coronary artery and 24 patients had two or three vessel disease. During exercise the mean ejection fraction increased from $47 \pm 12$ to $50 \pm 15(P<0.05)$ in patients with single vessel 
Table I Serial evaluation of resting left ventricular funcrion in 83 pasients after acule infarction. Changes in mean ejection fracton in patients with anterior and posterior miocardial infarction

\begin{tabular}{lcccc}
\hline $\begin{array}{l}\text { Ejection fraction } \\
(\%)\end{array}$ & $\begin{array}{c}\text { Total } \\
(n=83)\end{array}$ & $\begin{array}{c}\text { Anterior MI } \\
(n=42)\end{array}$ & $\begin{array}{c}\text { Posterior MI } \\
(n=41)\end{array}$ \\
\hline Initial & $50 \pm 13$ & $45 \pm 13$ & $* *$ & $56 \pm 11$ \\
14 days & $49 \pm 12$ & $44 \pm 12$ & $* *$ & $\begin{array}{c}54 \pm 9 \\
(n=31)\end{array}$ \\
& $(n=58)$ & $(n=27)$ & & $\begin{array}{c}5 \\
\text { Intial }\end{array}$ \\
4 months & $50 \pm 11$ & $46 \pm 11$ & $\Delta$ & $53 \pm 10$ \\
\hline
\end{tabular}

$\Delta=P<0.05$ and ${ }^{* *}=P<0.001$ for the comparison between anterior and posterior MI.

Table 2 Serial changes in left ventricular ( $L V$ ) ejection fraction at rest and during exercise in pattents with anterior and posterior myocardial infarction

\begin{tabular}{lccccc}
\hline $\begin{array}{l}\text { Ejection fraction } \\
(\%)\end{array}$ & & & Rest & Exercise \\
\hline 14 days & & & & \\
& Anterior MI & $n=42$ & $44 \pm 12$ & & $44 \pm 15$ \\
& Posterior MI & $n=41$ & $54 \pm 9$ & $* *$ & $57 \pm 10$ \\
& 1 v & $n=14$ & $53 \pm 6$ & $* *$ & $57 \pm 6$ \\
& $2-3$ v & $n=15$ & $54 \pm 10$ & & $56 \pm 11$ \\
4 months & Antenor MI & $n=27$ & $45 \pm 13$ & & $46 \pm 15$ \\
& Posterior MI & $n=31$ & $53 \pm 11$ & $* *$ & $57 \pm 12$ \\
\hline
\end{tabular}

$\mid \mathrm{v}=$ single vessel disease patıents; $2-3 \mathrm{v}=$ multivessel disease patients; **= $P<0.001$ for the comparison between anterior and posterior $\mathrm{MI}$ or single and multivessel disease

disease while it did not change in patients with multivessel disease. Of the group of patients with posterior infarction who underwent coronary angiography, 14 had single vessel disease and 15 multivessel disease; the former increased their ejection fraction during exercise from $53 \pm 6$ to $57 \pm 6$ $(P<0.001)$, while the latter did not (Table 2).

\section{REST-EXERCISE RADIONUCLIDE STUDIES AT 4 MONTHS}

The mean left ventricular ejection fraction at rest of the 58 patients who underwent an exercise radionuclide stress test was $49 \pm 12 \%$, comparable to the initial ejection fraction $(50 \pm 11 \%)$. The 27 patients with anterior myocardial infarction had a mean resting ejection fraction of $45 \pm 13 \%$, significantly lower than the mean value for the 31 patients with posterior infarction $(53 \pm 11 \%, P<0.05)$. However, for both groups, mean resting ejection fraction at 4 months was similar to the initial values (Table 1).
During the symptom-limited exercise test the mean work load was $76 \pm 31$ watts, the heart rate increased from $67 \pm 12$ to $116 \pm 19$ beats per minute and systolic blood pressure increased from $126 \pm 15$ to $175 \pm 12 \mathrm{mmHg}$.

The 27 patients with anterior myocardial infarction did not change their ejection fraction during exercise $(45 \pm 13 \%$ vs $46 \pm 15 \%)$, while 31 patients with posterior infarction increased their ejection fraction from $53 \pm 11 \%$ to $57 \pm 12 \% \quad(P<0.001)$ (Fig. 2). In the 35 patients who underwent early (14 days) and late (4 months) left ventricular assessment, mean ejection fraction values at rest did not show any significant change from day 1 values. During the predischarge exercise test 28 out of the 35 patients $(80 \%)$ failed to increase their ejection fraction by 5 points percent $(5 \mathrm{p} \%)$; the ejection fraction remained unchanged in 24 patients and decreased in four. At the 4 month evaluation the 


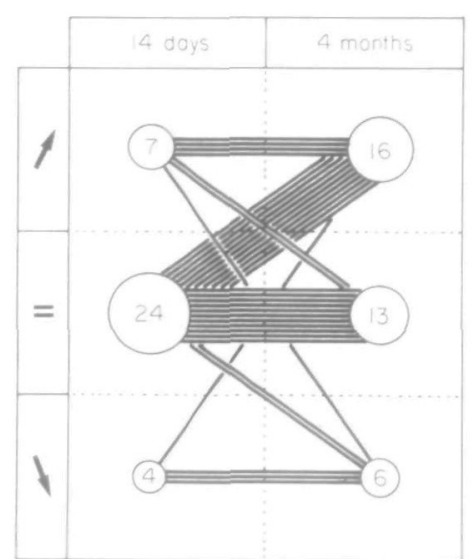

Figure I Changes in left ventricular ejection fraction (EF) from rest to exercise at 14 days and 4 months in 35 patients following acute myocardial infarction. Increase ( $\uparrow$ ) or decrease $(\downarrow)$ of ejection fraction by five points percent $(5 \mathrm{p} \%)$ or more. EF change inferior to $5 \mathrm{p} \%(=)$. Each line represents a patient.

ejection fraction response was abnormal in only 19 out of the 35 patients $(54 \%)$; the ejection fraction remained unchanged from rest in 13 patients and decreased in six (Fig. 1). The global improvement in left ventricular function was particularly evident in patients with posterior myocardial infarction.

\section{Discussion}

Several studies have shown that the ejection fraction calculated by invasive or noninvasive means during the acute phase of myocardial infarction can predict survival ${ }^{[25}$. Our data confirm previous studies and indicate the usefulness of the ejection fraction measured by radionuclide angiography within 24 hours after admission in identifying patients at high risk of death following acute myocardial infarction. Other studies showed that submaximal radionuclide exercise testing was a highly sensitive means of classifying patients at the time of hospital discharge after acute myocardial infarction according to the likelihood of having cardiac events during the ensuing 6 months ${ }^{[12.15]}$. From our study, however, no such data are available because only one out of the five patients who died in the 6 month follow-up underwent exercise radionuclide angiography before discharge.

This study also confirms other reports, showing that anterior myocardial infarction results in greater impairment of overall left ventricular function than does posterior infarction ${ }^{[6,12,18]}$.
Little information is available on the evolution of left ventricular performance at rest and during exercise in the recovery phase after myocardial infarction ${ }^{[5.6 .8]}$. We thus felt it was interesting to determine serially the different behaviour of left ventricular function at rest and during exercise in patients following acute myocardial infarction and to correlate the findings to the location of the necrosis and the extent of the coronary disease. Reduto et al. demonstrated little change in left ventricular function at rest, measured by first pass radionuclide angiocardiography, between 1 day and 2 weeks after recent myocardial infarction ${ }^{[6]}$. We noted, however, a trend indicative of slight deterioration during the period beginning at a mean of 28 hours after admission and ending before discharge in the total population as well as in patients with anterior or posterior myocardial infarction. The relative high initial ejection fraction could be explained by concomitant administration of vasodilating drugs such as intravenous nitroglycerine whereas more patients were on betablockers at the time of discharge. The results of this study indicate that before discharge from the hospital after acute myocardial infarction mean ejection fraction for the entire group varies little from rest to submaximal exercise. Only 26 of the 83 patients increased their ejection fraction by $5 p \%$ or more, while the other 57 patients showed a decreased or unchanged ejection fraction value.

In the subgroup of 41 patients with posterior myocardial infarction, however, ejection fraction increased significantly during exercise from the value at rest, while the average fraction for the patients with anterior infarction remained unchanged. These findings differ slightly from those of Pulido et al., who found a significant reduction in ejection fraction during exercise in patients with anterior myocardial infarction but no change in those with inferior infarction ${ }^{[17]}$. Mean ejection fraction during exercise increased significantly from rest value in patients found to have only one vessel disease, while it did not change in patients with multivessel disease. This could be explained by the fact that patients with single vessel disease tended to have wall motion abnormalities during exercise confined at the site of infarction while patients with multivessel disease developed wall motions abnormalities at different sites. Our findings are in agreement with those of Nicod et al. ${ }^{[10]}$.

For the entire group of patients recovering from myocardial infarction, left ventricular function showed no significant variation during exercise at 4 
months evaluation; however, marked intragroup variations were found. Patients with posterior myocardial infarction demonstrated a significant improvement in ventricular function during exercise as they did before hospital discharge, while patients with anterior myocardial infarction demonstrated no change in their ejection fraction during exercise.

\section{Conclusions}

Our results show that patients who died early after acute myocardial infarction had low initial ejection fractions and suggest that ejection fraction measured by radionuclide angiography 24 hours following the acute event is useful in predicting early mortality. Data collected 14 days and 4 months after infarction indicate that no significant change in ejection fraction occurred at rest or during exercise compared with values at rest for the group as a whole. However, ejection fraction value of patients with posterior myocardial infarction or that of patients with single vessel disease, increased with exercise, indicating that the capacity for improvement in myocardial function does exist in those patients who manifest the least extensive ischaemic or necrotic damage. Finally, left ventricular response to exercise in patients with anterior infarction can be predicted grossly from predischarge submaximal stress test and it seems that the symptom-limited exercise at 4 months adds little information.

\section{References}

[1] Killip T, Kimball JT. Treatment of myocardial infarction in a coronary care unit. Am J Cardiol 1967; 20: 457-64.

[2] Bigger JT, Heller CA, Wenger TL, Weld FM. Risk stratification after acute myocardial infarction. Am J Cardiol 1978; 42: 202-10.

[3] Greenberg R, McMaster P, Dwyer EM, The Multicenter post-infarction Research Group. Left ventricular dysfunction after acute myocardial infarction: results of a prospective multicenter study. J A C C 1984; 4: 867-74.

[4] Kupper W, Bleifeld W, Hanrath P, Mathey D, Effert S. Left ventricular hemodynamics and function in acute myocardial infarction: studies dunng the acute phase, convalescence, and late recovery. Am J Cardiol 1977; 40: 900-5.

[5] Schelbert HR, Henning H, Ashburn WL, Verba JW, Kaeliner JS, O'Rourke RA. Serial measurements of left ventricular ejection fraction by radionuclide angiocardiography early and late after myocardial infarction. Am J Cardiol 1976; 38: 407-15.
[6] Reduto LA, Gerber HJ, Cohen LS, Gottschalk A, Zaret BL. Sequential radionuclide assessment of left and right ventricular performance after acute transmural myocardial infarction. Ann Intern Med 1978; 89. 441-7.

[7] Rigo P, Murray M, Strauss HW et al. Left ventricular function in myocardial infarction evaluated by gated scintiphotography. Circulation 1974; 50: 678-84.

[8] Borer JS, Rosing DR, Miller RH et al. Natural history of left ventricular function during 1 year after acute myocardial infarction: comparison with clinical, electrocardiographic and biochemical determinations. Am J Cardiol 1980; 46: 1-12.

[9] Fioretti P, Brower RW, Simoons ML et al. Prediction of mortality in hospital survivors of myocardial infarction. Br Heart J 1984; 52: 292-8.

[10] Nicod P, Corbett JR, Firth BG et al. Prognostic value of resting and submaximal exercise radionuclide ventriculography after acute myocardial infarction in high-risk patients with single and multivessel disease. Am J Cardiol 1983; 52: 30-35.

[1 1] Hung J, Goris ML, Nash E, Kraemer HC, DeBusk RF. Comparative value of maximal treadmill testing, exercise thallium myocardial perfusion scintigraphy and exercise radionuclide ventriculography for distinguishing high- and low-risk patients soon after acute myocardial infarction. Am J Cardiol 1984; 53: 1221-7.

[12] Corbett JR, Drehmer GJ, Lewis SE et al. The prognostic value of submaximal exercise testing with radionuclide ventriculography before hospital discharge in patients with recent myocardial infarction. Circulation 1981; 64: $535-44$.

[13] Hirsowitz JS, Lakier JB, Marks DS, Lee TG, Goldberg $A D$, Goldstein S. Sequential radionuclide angiocardiographic assessment of left and right ventricular performance and quantitative thallium-201 scintigraphy following acute myocardial infarction. Am Heart J 1984; 107: 934-9.

[14] Olson HG, Lyons KP, Troop P, Butman S, Piters KM. The high-nsk acute myocardial infarction patient at 1-year follow-up: identification at hospital discharge by ambulatory alectrocardiography and radionuclide ventriculography. Am Heart J 1984; 107: 358-66.

[15] De Feyter PJ, van Eenige MG, Dighton DH, Visser FC, de Jong J, Roos JP. Prognostic value of exercise testing, coronary angiography and left ventriculography $6-8$ weeks after myocardial infarction. Circulation 1982; 66 : 527-36.

[16] Warnowicz MA, Parker H, Cheitlin MD. Prognosis of patients with acute pulmonary edema and normal ejection fraction after acute myocardial infarction. Circulation 1983; 67: 330-4.

[17] Pulido JI, Doss J, Twieg D et al. Submaximal exercise testing after acute myocardial infarction: myocardial scintigraphic and electrocardiographic observations. Am J Cardiol 1978; 42: 19-28.

[18] Russel RO, Hunt D, Rackley CE. Left ventricular hemodynamics in anterior and inferior myocardial infarction. Am J Cardiol 1973; 32: 8-16. 